\title{
Japanese public health nurses' culturally sensitive disaster nursing for small island communities
}

\author{
Miki Marutani \\ National Institute of Public Health, Japan \\ marutani.m.aa@niph.go.jp (corresponding author)
}

\author{
Shimpei Kodama \\ Department of Community Integrated Nursing, Kagoshima University, Japan \\ kodama@health.nop.kagoshima-u.ac.jp
}

\author{
Nahoko Harada \\ Department of Psychiatric and Mental Health Nursing, University of Miyazaki, Japan \\ nahoko-harada@umin.ac.jp
}

\begin{abstract}
Objective: To clarify the tacit knowledge of Japanese public-health nurses who administer culturally sensitive disaster nursing for small island communities. Design: Qualitative and inductive study. Sample: Eleven public-health nurses who provided disaster aid on one of six affected islands. Measurements: Semi-structured interviews, with qualitative analysis of data. Nursing actions that were based on consideration for islanders' culture were categorized in terms of similarity. Results: Categories of culturally sensitive disaster nursing were identified for each disaster phase of the recovery process. These included confirming islanders' safety and using existing interpersonal bonds to notify others (acute phase); assisting shelter management by facilitating the application of local rules and bonds (semi-acute phase); compensating for weakened neighbour-based relationships through public services (mid-term phase); and supporting the completion of necessary procedures by utilizing/adjusting islanders' existing relationships with local government personnel (long-term phase). Cultural elements included interpersonal bonds and relationship, which emerged across phases. Conclusion: Public-health nurses should utilize culture not only to comfort islanders, but also to strengthen their sense of coherence and resilience as islander. They should also remember the nursing principle of compensating for a lack of self-care. To provide effective aid, the changes in cultural influences with recovery phases should be considered.
\end{abstract}

Keywords: culture, disasters, islands, Japan, nursing, public health

https://doi.org/10.24043/isj.116 • Received October 2019, accepted March 2020

(C) 2020-Institute of Island Studies, University of Prince Edward Island, Canada. 


\section{Background: Need for intensive disaster preparedness for small island communities}

Island communities sometimes have many notable characteristics, such as access to and use of sea-based resources, resort environments, and unique cultures. These characteristics can develop because islands are relatively isolated environments compared to the nearby mainland (Royle, 2001); however, this can also mean they are vulnerable to hazardous natural phenomena (Kelman, 2018; United Nations, 2010). Many Asia-Pacific countries are Small Island Developing States (SIDS), and the region has frequent disasters. SIDS are especially diverse, and this should receive priority consideration when planning disaster prevention, mitigation, and restoration in such areas (Nunn et al., 2014; Walshe \& Stancioff, 2018).

As Campbell (2009) described for Pacific SIDS, islander traditional knowledge of the environment and numerous cultural forms have reduced some effects of environmental hazards, thus enabling sustained settlement, whether purposefully or incidentally. Rampengan et al. (2014) reported that a small village in Indonesia turned remoteness into the maximization of existing resources and the facilitation of innovation. Knowledge has been accumulating, but more is necessary to develop the literature on the disaster risk reduction (DRR) of small island communities.

\section{Importance of culturally sensitive disaster nursing}

As a result of continuing disasters worldwide, a range of global standards for disaster preparedness have been developed (Cox \& Briggs, 2004; World Health Organization \& International Council of Nurses, 2009; World Health Organization South-East Asia Region Office, 2011).

Culture, including local knowledge regarding natural phenomena, can have positive and negative effects on disaster risk reduction and post-disaster recovery (Kulatunga, 2010; OliverSmith, 1996). Thus, awareness of local cultural practices is necessary for effective preparation. Notably, survivors not only represent individuals who require support, but also examples of resilience (Deeny et al, 2010). For instance, communities that reconstruct their own houses after disasters can have more successful recovery processes than communities that have donated houses; this is because the latter group have higher dependency (Ratnayake \& Rameezdeen, 2008).

According to the International Federation of the Red Cross (2013), nurses must respect local culture. The importance of cultural competency (Bergeron, 2015; Deeny \& Mcfetridge, 2005; Society of Research Administrators International, 2008) and culturally sensitive care (Danna \& Bennett, 2013; Varghese, 2010) have been highlighted as possible means of saving lives and enhancing communities' resilience. Existing programs, however, mainly focus on minorities, such as immigrants or indigenous peoples in western countries; therefore, there is a need to investigate the effectiveness of cultural competency in regard to disaster nursing in eastern regions (The Society of Research Administrators International, 2008).

\section{Clarifying the tacit knowledge of culturally sensitive disaster nursing}

Unfortunately, most disaster-preparedness plans do not consider local culture (Hoffman, 1999; Wisner et al., 2004). There have been cases of nurses providing disaster nursing in accordance with local cultures, but there is little reference to local culture in disaster-nursing 
textbooks or articles. Further, there is a lack of educational programs, especially in western countries, regarding such matters aside from linguistic topics (Danna et al., 2015).

Japanese public-health nurses (PHNs) provide culturally sensitive care in normal and post-disaster phases, because they focus on certain geographical areas and administer health programs to all residents based on a community diagnosis (Murashima et al., 1999). From the perspective of public health, rather than providing disaster-response emergency care, PHNs provide health-crisis management. The nurses' skills in this regard are based on tacit knowledge (Leininger, 1991). Efforts should be made to develop such skills into sharable guidelines for use not only on Japanese islands, but also around the world, which accords with the United Nations' motto of 'leaving no one behind' (United Nations, 2016).

\section{Research question}

The aim of this study is to clarify the tacit knowledge used by Japanese PHNs when providing culturally sensitive disaster nursing on small islands.

\section{Definitions}

\section{Culture}

Culture has been defined by a wide range of researchers. According to Taylor (1924, p. 1), culture is a "complex whole which includes knowledge, belief, art, morals, law, and any other capabilities and habits acquired by man as a member of society." Leininger (1991) later suggested that culture is the broadest, most comprehensive, holistic, and universal feature of human beings. Giger (2016) described culture as being shaped by values, beliefs, norms, and practices that are shared by members of the same cultural groups. Purnell (2013) defined culture as the totality of socially transmitted behavioural patterns, arts, beliefs, values, customs, lifeways, and all other products of populations that guide a world view and decision-making. Overviewing these definitions, in the present study we define culture as thoughts, attitudes, and behaviours that are based on values, beliefs, and norms, and that are commonly observed among people in communities.

\section{Disaster}

Definitions of disaster are shown in Table 1. In the present study, we defined disaster by focusing on aspects of life that comprise the continuum of daily activities that are shaped by culture (Henderson, 1997; Leininger, 1991; Roper, Logan, \& Tierney, 2013).

Table 1. Definition of a disaster.

"A serious disruption of the functioning of a society, causing widespread human, material, or environmental losses that exceed the ability of the affected population to cope using its own resources." (United Nations Office for Disaster Risk Reduction, 2009)

"Any occurrence that causes damage, ecological disruption, loss of human life, or deterioration of health and health services on a scale sufficient to warrant an extraordinary response from outside of the community or area." (World Health Organization, 2007) 
As a result, we developed the following definition of disaster: phenomena that interrupt streams of life in communities, and that prevent people from meeting their basic needs. This study limits the scope of this term to disasters involving environmental hazards such as earthquakes, typhoons, and volcanic eruptions to remain within the aim of this study.

\section{Methods}

Design and sample

An inductive qualitative design was applied in this research. This study was conducted on six islands around Japan which had been affected by disasters involving natural hazards occurring between 2011 and 2016 (Table 2). Participants were recruited by snowballing with the criteria: over 10 years with working experience with expecting the knowledge of culture; have experience to provide disaster-related aid on their islands. As a result, 11 local public health nurses (PHNs) with 23 years (range: 13-34) average working experience were included.

Table 2. Characteristics of the examined islands.

\begin{tabular}{lllllll}
\hline Island name & A & B & C & D & E & F \\
\hline Population & 130 & 3000 & 208 & 40000 & 8000 & 2700 \\
Hazard classification & Volcanic & Volcanic & Heavy & Heavy & Heavy rain & Landslide \\
& eruption & eruption & rain & rain & & \\
No. of deaths & 0 & 0 & 0 & 3 & 40 & 1 \\
Houses damaged & 0 & 0 & 5 & 150 & 43 & 11 \\
\hline
\end{tabular}

\section{Measures}

Semi-structured interviews were conducted by the first and second authors from March 2017 to June 2018. PHNs were asked, using an interview guide, about the disaster aid they provided, along with the associated time frame; nursing practices they provided that were influenced by considerations of the local culture; and nursing practices that were effective for comforting affected islanders. All interviews were audio-recorded, and lasted 90-110 minutes.

\section{Analytic strategy}

Interviews were conducted in Japanese by native speakers. They were transcribed verbatim, and interview notes and analytic memos were used during data analysis. Transcripts were analyzed using qualitative descriptive analysis. Participants were anonymized and a letter of the alphabet was assigned to each, starting with 'a' as participant number one.

First, transcribed interview data were categorized into meaningful segments that comprised descriptions of actions that contained expressions relating to culture. Then, codes, which comprised nursing actions that were performed in consideration of islanders' culture, were created from the segments.

Next, codes were sorted into four disaster phases according to duration: acute (onset of the hazard to 72 hours), semi-acute (72 hours to 1 month), mid-term ( 1 month to 1 year), and long-term (over 1 year). Then, codes for each disaster phase were compared in terms of similarities and differences, with similar codes grouped to create categories of culturally sensitive disaster-nursing actions. 
Third, the expressions used in each code were examined, and those that related to culture were extracted. These expressions were then abstracted and categorized to identify the kinds of culture PHNs considered during each phase.

To ensure the trustworthiness and rigour of our analysis, credibility, applicability (Corbin \& Strauss, 2008), dependability, confirmability, and transferability (Lincoln \& Guba, 1985) criteria were applied. The first and second authors had experience of studying disaster nursing on islands, and conducted all interviews in this study to ensure quality data collection. Also, the interviewers visited and observed affected areas with the PHNs, and listened to the islanders' accounts to gain an in-depth understanding of the phenomena (credibility). Interviews were conducted in the participants' offices and recorded and transcribed verbatim, and multiple memos were written to reflect the interview data (confirmability, dependability). The study process and results were repeatedly examined by two researcher nurses who were specialists in disaster and public-health nursing. Also, the ongoing analyses were examined by two researchers who were specialists in disaster medicine and island features (credibility, dependability). Finally, PHNs who had experience of island-related disasters reviewed the findings and verified that the results resembled their own experiences (applicability, transferability). After analyzing the $11^{\text {th }}$ interview, no further changes to major categories and phases were deemed necessary, and we concluded the data collection and analyses (theoretical saturation).

\section{Ethical considerations}

Participants were informed of the purpose, procedure, voluntary nature, confidentiality, and potential contributions of this study. Written informed consent was obtained from all participants and their supervisors. The study protocol was approved by the ethical board of the institution with which the first author is affiliated (No. 360).

\section{Results}

In each disaster phase, PHNs mainly performed management, such as information exchange or shelter arrangement, and also provided support for self-care, all of which was based on consideration for island culture. Further, cultural elements such as bonds and relationships with islanders were utilized.

\section{Culturally sensitive disaster nursing in each phase}

Categories of culturally sensitive disaster nursing in each disaster phase are shown in Table 3. Details of the categories are provided below, with examples of quotes presented in italics, with the anonymized name of PHNs indicated as letters in parentheses at the end of quotation. 
Table 3. Categories of culturally sensitive disaster response.

\begin{tabular}{ll}
\hline Phase & Category \\
\hline Acute & Confirming islanders' safety and notifying others using existing interpersonal bonds \\
& Collecting information/supplements and distributing them using the islanders' existing networks \\
Opening evacuation centres or first-aid stations using local industrial facilities
\end{tabular}

Culturally sensitive disaster nursing in each phase: Acute phase

Upon arriving at temporary refuges, the PHNs' first action was to confirm the safety of islanders who were not present, and to then notify and comfort those in the refuges. To achieve this, the nurses utilized islanders' existing bonds:

The man, who had been caring for his neighbours as well as he had cared for himself, informed me of the safety of those who had been missing after the flood. (PHN y)

I let a woman visit all of the evacuation centres on the island and inform the occupants of the islanders' safety. This comforted the other evacuees, because she knew all of the islanders like family. Her influence was greater than that of a formal presence. (PHN u)

Simultaneously, to provide appropriate disaster aid, they collected information/supplements and distributed them using the islanders' networks: 
The drugstore owner, a longtime acquaintance of mine, called me, called me on my way to the town hall and offered all of the hygiene materials in his store. (PHN r)

They opened evacuation centres or first-aid stations using local industrial facilities:

Designated sites were damaged, so we used a sight-seeing centre as the first-aid centre, because we knew that there would be enough utilities there to provide first aid. (PHN q)

Culturally sensitive disaster nursing in each phase: Sub-acute phase

After shelters opened, PHNs helped the islanders who were managing the shelters by allowing them to apply local rules and consider existing bonds:

We let them decide their own living space in the shelters based on their own kind of hierarchy, because their tacit social order seemed rational and autonomous. (PHN x)

After addressing early impacts, local government staff and non-affected islanders were gradually congregated. The PHNs designated and limited certain forms of support, considering the characteristics of the residents:

Although the national manual says that local PHNs should manage disaster aid and that relief nurses should directly care for evacuees, we designated local PHNs to home-visiting teams, as the islanders had a generally retiring nature towards outsiders. (PHN s)

We limited volunteering, considering the islanders' autonomous character; they then made their own rules and roles in the shelter and in the devastated village. (PHN r)

While designating staff, the PHNs determined evacuees' needs by considering the islanders' character:

Since we knew that the islanders would be reluctant to discuss their problems, we tried to determine their needs from their facial expressions. (PHN w)

To continue providing efficient health care, PHNs utilized existing close relationships between medical staff and neighbours:

One local healthcare volunteer told me that she had ensured that her neighbour, who had schizophrenia, continued taking his medication after the flood, and that she was willing to report on his condition. (PHN y)

While aiming to prevent infections, PHNs respected the islanders' customs as much as possible, giving suggestions rather than orders:

We provided plastic wraps, offered by drugstores, to those who gathered at the shelter to make rice-balls. We recommended that they utilize these to make the rice- 
balls cleanly, even though their own cooking practices, making rice-balls with their bare hands, were well-intentioned. (PHN p)

As most islanders loved their island, they found it difficult to accept that it had caused them to suffer (i.e., through the disaster). The PHNs helped them accept the disaster, applying the islanders' own view of nature.

She repeatedly told me of how blessed and graceful the sea and the island's mountains are, and I listened to her intently. (PHN u)

\section{Culturally sensitive disaster nursing in each phase: Mid-term phase}

In the mid-term phase, shelters began to close and evacuees started new lives in temporary houses. The mutual support among the islanders consequently weakened because they were assigned to isolated shelters or temporary houses. The PHNs endeavoured to compensate for this loss of mutual support through providing public services:

We advocated the local government that until the islanders restored the car-sharing systems they had employed on the island, the routes of the community buses were modified to stop by the temporary houses.

As a result of the devastation to or isolation from their island, the islanders needed to reconstruct their lives and compensate for their weakened relationships with nature:

Daycare programs were introduced for an older adult with dementia until he could return to the island. This was because he had left the island and the fields that he had continued to cultivate even after developing dementia. (PHN r)

Aiming at effective provision of support, PHNs respected the islanders' character, pace, and attachment to the island:

We did not rush to implement support, but proceeded at the islanders' pace; otherwise, we would lose their trust and they would lose their motivation to recover. (PHN x)

PHNs recommended islanders balance their customs with their new, unfamiliar lifestyles and/or medical needs to prevent secondary health impairments:

The older farmers were gradually eating less day-by-day. This was because they were now buying all of their food, but had previously gotten food from their fields in a self-sufficient manner. So, we recommended that they care for small fields offered by the local government, and they eventually regained their appetite. (PHN r)

The amount of alcohol consumption was a kind of health barometer on the island. When we noticed a pile of empty liquor bottles behind the temporary houses, we visited a middle-aged fisherman and discussed his concerns. (PHN r) 
It took several weeks for transportation to be restored; as a result, PHNs managed healthcare/supplements by fostering close relationships with medical staff/neighbours:

One older woman needed medication, but could no longer access the clinic because she had been moved from the evacuation centre to an isolated house. However, a local government officer, a man she had cared for when he was a child, willingly brought her the medication because his home was next to her new house. (PHN z)

PHNs anticipated that relationships among islanders would deteriorate in the tiny shelters as time passed. Consequently, they reconstructed or maintained good relationships among the residents by preventing or resolving conflicts:

As the islanders could be both supportive and meddlesome, we identified quiet people and sat with them until they told us what was troubling them. (PHN s)

Being aware of the islanders' strong pride in their ability to cope with disasters, PHNs repeatedly mentioned it in conversation in order to enhance their resilience:

One older man told me that the mountain had regained its greenery after the previous eruption, and I nodded passionately, because such a symbol could convince him the recovery was continuing. (PHN t)

Culturally sensitive disaster nursing in each phase: Long-term phase

In the long-term phase, most evacuees moved to their new or reconstructed houses. The islanders were required to negotiate several administrative procedures, such as matters relating to medical or housing subsidies. PHNs supported them by utilizing or adjusting kin-based relationships with the local government:

One local government clerk was affected by the eruption, but performed most of the administrative procedures for the islanders because he was related to them. However, his undertakings exhausted him, so we sourced additional clerks to help the islanders on a one-to-one basis. (PHN v)

Also, some islanders, especially frail older adults, had to decide whether to stay on the island or leave the island and move into their children's homes. PHNs helped them make the decision while respecting their character and attachment to the island:

One older woman preferred her autonomous farming life to daycare programs in urban cities, so we provided formal and informal services to help her return to the island. (PHN z)

Most islanders had a dual life, on the island and the mainland; PHNs utilized such a lifestyle to reconstruct the healthcare network: 
During the recovery, we reconnected the clinic on the island with the hospitals on the mainland. This allowed the islanders to see a specialist and use the new communication tools that were not available to them before the eruption. (PHN q)

PHNs tried to make existing bonds more flexible to reconstruct or reinforce the community against the next disaster:

We admired the close relationships among the native islanders, but hoped to make it more inclusive, so we tried to involve newcomers in health-promoting programs such as exercise programs. This was because, while the flood was tragic, it was a good chance to undo the exclusivity that had overwhelmed the island. (PHN u)

The islanders were very familiar with the plural aspects of nature: a blessing and a danger, so PHNs recreated health-promotion and disaster-prevention programs based on this view of nature:

Adopting an accepting attitude towards a small typhoon may be necessary to live with nature, but we proposed that the community leaders engage in the new disaster-simulation programs, mentioning that nature does not change, but people get older. (PHNs t)

Table 4. Cultural elements.

\begin{tabular}{|c|c|c|}
\hline Phase & Category & Examples of culture-related expressions \\
\hline \multirow[t]{3}{*}{ Acute } & Bond & Caring for others as well as one cares for oneself, interdependent, like family \\
\hline & Network & longtime acquaintance, relationships with neighbours, women's association \\
\hline & Working style & Sight-seeing centre, barn, job farm \\
\hline \multirow{6}{*}{$\begin{array}{l}\text { Sub- } \\
\text { acute }\end{array}$} & Local rules & Hierarchy, tacit ranks, manner of decision-making \\
\hline & Bond & Interdependent, supportive of each other, mutual care \\
\hline & Character & Modest, closed relationship, few words, retiring, hesitative, persevering \\
\hline & Relationship & Close, like family, supportive \\
\hline & Customs/habits & Eating habits, bathing style, sanitation practices, cooking practices \\
\hline & View of nature & $\begin{array}{l}\text { In awe of nature, friendly relationship with the sea, appreciative of the } \\
\text { volcano, the blessing of the sea, graceful mountain }\end{array}$ \\
\hline \multirow{8}{*}{$\begin{array}{l}\text { Mid- } \\
\text { term }\end{array}$} & Relationships & Car-sharing system, helping, visiting, supporting neighbours, knowing each \\
\hline & Relationship & other like family \\
\hline & with nature & Nature embraces the islanders, rich environment, open space \\
\hline & Character & Hesitative, modest, reserved \\
\hline & Time sense & Slow pace, past-oriented, context \\
\hline & Customs/habits & Alcohol consumption, eating habits, hygiene practice, self-sufficiency \\
\hline & Bond & Nasty relationship, exclusivity, intimately familiar with each other \\
\hline & $\begin{array}{l}\text { Attachment to } \\
\text { the island }\end{array}$ & Pride in island life, love of nature, appreciative of the environment \\
\hline \multirow{6}{*}{$\begin{array}{l}\text { Long- } \\
\text { term }\end{array}$} & Character & Hesitative, modest, obstinate \\
\hline & Place attach. & Pride in autonomy, appreciative of the environment, love for neighbours \\
\hline & Dual life & Go to local government offices, visit doctor, go shopping, \\
\hline & Relationships & Kin-based, dependent \\
\hline & Bond & Closed, exclusive, inner-oriented mutuality, supportive \\
\hline & View of nature & Unchanging, restorable, stormy and peaceful \\
\hline
\end{tabular}




\section{Cultural elements}

Cultural elements for each phase were categorized as shown in Table 4. Some categories emerged repeatedly, such as 'bond', 'relationship', and character'.

\section{Discussion}

Nursing actions based on cultural considerations: Acute phase

Collecting and distributing information and relief goods is mentioned in existing disaster nursing (Stanley, Farra, \& Hssniller, 2015). Contrarily, actions such as distributing information regarding islanders' safety and supplying goods using existing bonds or networks are not described in any guidelines or textbooks. Notifying islanders of family members' safety and obtaining necessities are important comforting measures.

In post-disaster periods, utilizing culture-related factors such as bonds, networks, and working style instead of formal approaches can result in more efficient and effective activities (Bergeron, 2015). Further, such isolated situations require a sharing approach, such as social cohesion (Gaillard, 2007).

Nursing actions based on cultural considerations: Sub-acute phase

When creating safe care environments (World Health Organization, \& International Council of Nurses, 2009), employing staff members who have awareness of tacit local rules or local character comforts islanders and allows them to develop 'manageability' (i.e., an individual's belief that things are manageable and within his/her control) (Antonovsky, 1987). Such a skill is important for enhancing resilience.

Prompt assessment and care are required in this phase (Stanley, 2015). Considering the islanders' character and utilizing existing relationships increased the efficiency of the disaster aid. Further, utilizing neighbourhood help fostered manageability. Preventing infection is also important (Lavin, 2014; Stanley, 2015); however, when changing customs/habits is required to prevent infection, considering the culture is beneficial (Australian Government, Department of Foreign Affairs and Trade, 2013).

Disaster could cause a loss of identity (Dugan, 2007) or loss of faith in nature (Cassim, Stolte, \& Hodgetts, 2015), especially in rural areas. Accepting islanders' feelings until they restore their sense of comfort allows them to retain their identity.

Nursing actions based on cultural considerations: Mid-term phase

The PHNs did not use paternalistic methods, instead compensating for weakened human support or a loss of access to natural resources by modifying bus routes or introducing daycare programs. These culturally sensitive support methods could enhance islanders' manageability, as could other culturally sensitive actions such as providing support at islanders' pace; balancing their traditional customs with their new, unfamiliar lifestyles; and utilizing existing relationships. Also, pride in their lifestyle in the island may have instilled meaningfulness (a sense of coherence that is essential for resilience) (Antonovsky, 1987). Contrarily, harmful habits such as excess alcohol consumption and prying should be repatterned, as described in existing cultural-care recommendations (Leininger, 1991). 
Nursing actions based on cultural considerations: Long-term phase

Advocating for recovery is an element of the framework of community recovery (World Health Organization, \& International Council of Nurses, 2009). The PHNs we interviewed advocated adding clerks to help older adults. This instilled manageability not only in resident clerks, but also older islanders, who would also support decision-making. Collaborations with various groups are required to reinforce networks (World Health Organization, \& International Council of Nurses, 2009), and this is especially important on isolated islands (i.e., through collaborating with the mainland). Capitalizing on the dual life between islands and the mainland/main islands is effective for reinforcing networks. Also, utilizing new equipment for collaboration infuses new culture into traditional cultures, and increases the flexibility of bonds and health-promotion/disaster-prevention programs. This facilitates change in the patterns of knowledge, practice, and values required to address climate change (Walker et al., 2011).

\section{Cultural elements: Categories of cultural elements}

Most cultural elements observed in this study have previously been noted (Leininger, 1991; Giger, 2016; Purnell, 2013), but our descriptions are slightly more detailed. For example, 'bond' is a kind of 'kinship' (Leininger, 1991) or 'social organization (Giger, 2016), but has a deeper meaning, represented by the PHNs' expressions caring for his neighbours as well as he had cared for himself and prying relationship. Also, 'character' is a form of 'communication' (Giger, 2016; Purnell, 2013), but includes backgrounds such as boundaries, as indicated by retiring nature towards outsiders.

Attachment to islands is not found in any cultural-care textbooks (Giger, 2016; Purnell, 2013). Existing textbooks mainly mention immigrants' cultures, focusing only on national origin or place of birth. However, some literature has mentioned that attachment to a place or community functions as a means of addressing vulnerabilities (Howell \& Fielding, 2019). Disaster-aid teams should consider islanders' attachment to their home regions.

\section{Cultural elements: Influence of culture}

The same culture-related categories repeatedly emerged across the disaster phases, but with differing influence. For instance, in the acute phase 'bond' functioned as a means of conveying the islanders' safety between PHNs and islanders who cared for neighbours as well as they cared for themselves. On the other hand, in the mid-term phase it was considered something prying that might cause trouble in tiny shelters. In the long-term phase, it modified from exclusivity to flexibility as a bond that connects old and new residents.

Neither disaster-nursing nor cultural-nursing guidelines mention that the influence of culture changes with disaster phase. It is important for disaster-aid members to be aware of such change.

\section{'Islandness' in this study}

The material expression of islandness is sometimes said to be characterized by a body of land surrounded by water, as well as isolation and bounded spaces (Royle, 2001). Bates et al. (2019) states these characteristics are insufficient, and that, instead, subjective experience is the central feature of islandness. The findings of this study could show how to combine subjective experience as islandness (i.e., bonds, tacit local rule, habits, etc.) and standards of disaster 
nursing (i.e., distributing information, creating safe care environments, preventing infection, etc.). This could be a framework for combining indigenous and Western knowledge within DRR in small islands (Mercer et al., 2007).

The comparison of disaster nursing according to islandness with basic nursing according to Maslow's basic needs (i.e., physiological needs, safety needs, love and belonging, esteem, self-actualization) (Maslow, 1943) can provide detailed perspectives. However, further investigation is required to clarify this.

\section{Implications, generalizations and limitations}

In disaster nursing, PHNs should utilize forms of culture such as bonds and relationships to distribute information and supplements. Respecting culture such as local rules and character instills manageability in affected islanders, and can also provide compensative help. Also, aid teams should consider people's attachment to the island and the changing influence of culture through disaster phases.

PHNs should obtain clear knowledge of island cultures continuously according to cultural humility (Hook et al., 2013) and share this with support nurses when necessary, meaning that islanders' experiences would offer to others insights into means of adaptation (Thompson, 2008). Our study findings could also offer insights for other islanders or indigenous peoples, who may have a different interpretation of cultures at risk of disasters affecting islands.

However, the number and areas of study were limited; additional research on other islands around the world is required to obtain accumulated data. Further, although experts cross-checked the analysis, the possibility of subject bias cannot be disregarded. We should critique and refine our study through further investigation.

\section{References}

Antonovsky, A. (1987). Unravelling the mystery of health. San Francisco: Josey Bass.

Australian Government, Department of Foreign Affairs and Trade (2013). Cultural and linguistic diversity (CALD) strategy 2018-2021. Retrieved from https://www.dfat.gov.au/sites/default/files/cald-strategy-2018-2021.pdf

Bates, L., Coleman, T., Wiles, J., \& Kearns, R. (2019). Older residents' experiences of islandness, identity and precarity: Ageing on Waiheke Island. Island Studies Journal, 14(2), 171-192. https://doi.org/10.24043/isj.92

Bergeron, W.P. (2015). Considering culture in evacuation planning and consequence management. Journal of Emergency Management, 13(2), 87-92. https://doi.org/10.5055/jem.2015.0222

Cassim, S., Stolte, O., \& Hodgetts, D. (2015). Metonymic objects, cultural practices and narrative repair: Sri Lankan responses to the Indian Ocean tsunami. Journal of Health Psychology, 20(7), 974-983. https://doi.org/10.1177/1359105313504442

Campbell, J. (2009). Islandness: Vulnerability and resilience in Oceania. Shima, 3(1), 85-97. 
Corbin, J., \& Strauss, S. (2008). Basics of qualitative health research: Techniques and procedures for developing grounded theory. Thousand Oaks, CA: Sage. https://doi.org/10.4135/9781452230153

Cox, E., \& Briggs, S. (2004). Disaster nursing new frontiers for critical care. Critical Care Nurse, 24(3), 16-22. https://doi.org/10.4037/ccn2004.24.3.16

Danna, D., \& Bennett, M.J. (2013). Providing culturally competent care during disasters: Strategies for nurses. Journal of Continuing Education in Nursing, 44(4), 151-152. https://doi.org/10.3928/00220124-20130327-13

Danna, D.M., Pierce, S.S., Schaubhut, R.M., Billingsley, L., \& Bennett, M.J. (2015). Educating nurses to provide culturally competent care during disasters. Journal of Continuing Education in Nursing, 46(3), 135-144. https://doi.org/10.3928/00220124-20150220-18

Deeny, P., Vitale, C.T., Spelman, R., \& Duggan, S. (2010). Addressing the imbalance: Empowering older people in disaster response and preparedness. International Journal of Older People Nursing, 5(1), 77-80. https://doi.org/10.1111/j.1748-3743.2009.00204.x

Deeny, P., \& Mcfetridge, B. (2005). The impact of disaster on culture, self, and identity: Increased awareness by health care professionals is needed. Nursing Clinics of North America, 40(3), 431-440. https://doi.org/10.1016/j.cnur.2005.04.012

Dugan, B. (2007). Loss of identity in disaster: how do you say goodbye to home? Perspectives in Psychiatric Care, 43(1), 41-46. https://doi.org/10.1111/j.1744-6163.2007.00105.x

Gaillard, J.C. (2007). Resilience of traditional societies in facing natural hazards. Disaster Prevention and Management, 16(4), 522-544. https://doi.org/10.1108/09653560710817011

Giger, J. (2016). Transcultural nursing: Assessment and intervention ( $7^{\text {th }}$ ed.). New York: Mosby. Henderson, V. (1997). Basic principles of nursing care. Geneva: International Council of Nurses. Hoffman, S.M. (1999). Anthropology and the angry earth: An overview. In A. Oliver-Smith \& S.M. Hoffman (Eds.). The angry earth: Disasters in anthropological perspective (pp. 1-16). New York: Routledge. https://doi.org/10.4324/9780203821190

Hook, J.N., Davis, D.E., Owen, J., Worthington, E.L., \& Utse, S.O. (2013). Cultural humility: Measuring openness to culturally diverse clients. Journal of Counseling Psychology, 60(3), 353-366. https://doi.org/10.1037/a0032595

Howell, L., \& Fielding, R. (2019). Motivating sustainable behavior: Waste management and freshwater production on the Caribbean island of Saint Barthélemy. Island Studies Journal, 14(1), 9-20. https://doi.org/10.24043/isj.74

International Federation of the Red Cross (2013). Cultures and disasters II: Exploring the links between disasters and culture(s): Preparedness, response, policies. Interdisciplinary Conference, Erlangen, Germany. Retrieved from http://culturesanddisasters.org/wp/about-cultures-and-disasters-ii-2013/

Kelman, I. (2018). Islandness within climate change narratives of small island developing states (SIDS). Island Studies Journal, 13(1), 149-166. https://doi.org/10.24043/isj.52

Kulatunga, U. (2010). Impact of culture towards disaster risk reduction. International Journal of Strategic Property Management, 14(4), 304-313. https://doi.org/10.3846/ijspm.2010.23

Lavin, R. (2014). Being prepared: Impact of disaster, terrorism, and war. In J.A. Allender, C. Rector, \& K.D. Waner (Eds.). Community \& public health nursing ( $8^{\text {th }}$ ed., pp. 537-567). New York: Wolters Kluwer Health. 
Leininger, M.M. (1991). Culture care diversity and universality: A theory of nursing. New York: National League for Nursing Press.

Lincoln, Y.S., \& Guba, E. (1985). Naturalistic inquiry. Newbury Park: Sage.

Maslow, A. (1943). A theory of human motivation. Psychological Review, 50(4), 370-396.

Mercer, J., Dominey-Howes, D., Kelman, I., \& Lloyd, K. (2007). The potential for combining indigenous and Western knowledge in reducing vulnerability to environmental hazards in small island developing states. Environmental Hazards, 7(4), 245-256. https://doi.org/10.1016/j.envhaz.2006.11.001

Murashima, S., Hatono, Y., Whyte, N., \& Asahara, K. (1999). Public health nursing in Japan: New opportunities for health promotion. Public Health Nursing, 16(2), 133-139. https://doi.org/10.1046/j.1525-1446.1999.00133.x

Nunn, P.D., Aalbersberg, W., Lata, S., \& Gwilliam, M. (2014). Beyond the core: Community governance for climate-change adaptation in peripheral parts of Pacific Island Countries. Regional Environmental Change, 14(1), 221-235. https://doi.org/10.1007/s10113-013$\underline{0486-7}$

Oliver-Smith, A. (1996). Anthropological research on hazards and disasters. Annual Review of Anthropology, 25, 303-328. https://doi.org/10.1146/annurev.anthro.25.1.303

Purnell, L.D. (2013). Transcultural health care: A culturally competent approach (4 $\left.4^{\text {th }} \mathrm{ed}.\right)$. Philadelphia: F.A. Davis.

Rampengan, M.M.F., Boedhihartono, A.K., Law, L., Gaillard, J.C., \& Sayer, J. (2014). Capacities in facing natural hazards: A small island perspective. International Journal of Disaster Risk Science, 5, 247-264. https://doi.org/10.1007/s13753-014-0031-4

Ratnayake, R.M.G.D., \& Rameezdeen, R. (2008). Post disaster housing reconstruction: Comparative study of donor driven vs. owner driven approach. In K. Keraminiyage, S. Jayasena, R. Haigh \& D. Amaratunga (Eds.). Post disaster recovery challenges in Sri Lanka: A collection of research papers based on a series of undergraduate research works carried out in Sri Lanka in 2007 (pp. 51-61). Manchester: School of the Built Environment, University of Salford. https://doi.org/10.1177/2158244015583072

Roper, N., Logan, W.W., \& Tierney, A.J. (2013). A model for nursing based on a model of living. In M.R. Alligood (Ed.). Nursing theorists and their work ( ${ }^{\text {th }}$ ed., pp. 52-54). St. Louis: Mosby.

Royle, S.A. (2001). A geography of islands: Small island insularity. New York: Routledge.

Society of Research Administrators International (2008). Cultural competency in disaster response: A review of current concepts, policies, and practices. Report prepared for the Office of Minority Health. Rockville: SRA.

Stanley, S.A.R., Farra, S.L., \& Hssniller, S.B. (2015). Public health nursing practice and the disaster management cycle. In M. Stanhope \& J. Lanvaster (Eds.). Public health Nursing: Population-centered health care in the community (9 ${ }^{\text {th }}$ ed., pp. 503-528). St. Louis: Elsevier.

Taylor, W. (1924). Primitive culture (7 $7^{\text {th }}$ ed.). New York: Brentano's.

Thompson, E. (2008). Acceptance speech by Senator Elizabeth Thompson recipient of 'The Champion of the Earth Award 2008': Latin America and Caribbean United Nations Environment Program, Nairobi.

United Nations (2010). Trends in sustainable development: Small island developing states (SIDS). New York: UN Press. 
United Nations (2016). The sustainable development goals report 2016. Retrieved from https://unstats.un.org/sdgs/report/2016/leaving-no-one-behind

United Nations Office for Disaster Risk Reduction (2009) UNISDR terminology on disaster risk reduction. Retrieved from https://www.unisdr.org/we/inform/publications/7817

Varghese, S.B. (2010). Cultural, ethical, and spiritual implications of natural disasters from the survivors' perspective. Critical Care Nursing Clinics of North America, 22(4), 515-522. https://doi.org/10.1016/j.ccell.2010.09.005

Walker, R., Hassall, J., Chaplin, S., Congues, J., Bajayo, R., \& Mason, W. (2011). Health promotion interventions to address climate change using a primary health care approach: A literature review. Health Promotion Journal of Australia, 22(4), 6-12. https://doi.org/10.1071/HE11406

Walshe, R.A., \& Stancioff, C.E. (2018). Small island perspectives on climate change. Island Studies Journal, 13(1), 13-24. Retrieved from https://doi.org/10.24043/isj.56

Wisner, B., Blaikie, P., Cannon, T., \& Davis, I. (2004). At risk: Natural hazards, people's vulnerability and disasters $\left(2^{\text {nd }} \quad\right.$ ed.). London: Routledge. https://doi.org/10.4324/9780203428764

World Health Organization, \& International Council of Nurses (2009). ICN Framework of disaster nursing competencies. Geneva: WHO \& ICN.

World Health Organization South-East Asia Region Office (2011). Regional case study on role of nurses and midwives in emergencies and disasters. Expert Meeting on Emergency and Disaster Nursing 28-30 September 2011, Jakarta, Indonesia. Retrieved from http://origin.searo.who.int/entity/nursing midwifery/topics/nursing/regionalcasestudy.pdf

World Health Organization (2007). Risk reduction and emergency preparedness WHO sixyear strategy for the health sector and community capacity development. Retrieved from https://www.who.int/hac/techguidance/preparedness/emergency preparedness eng.pd 